\title{
Polypoid melanoma and superficial spreading melanoma - different subtypes in the same lesion
}

\author{
Renato Shintani Hikawa ${ }^{1}$ \\ Mílvia Maria Simões e Silva Enokihara ${ }^{1}$ \\ Sérgio Henrique Hirata ${ }^{1}$
}

\author{
Eliza Sayuri Kanehisa ${ }^{1}$ \\ Mauro Yoshiaki Enokihara ${ }^{1}$
}

DOI: $h$ ttp://dx.doi.org/10.1590/abd1806-4841.20142802

\begin{abstract}
Melanoma is a malignant melanocytic neoplasm with high mortality rate, and steadily and universally increasing incidence rates. Polypoid melanoma is considered an exophytic variant of the nodular subtype. The incidence of polypoid melanoma is extremely variable, most likely because of the different criteria used for its characterization. We presented a rare case of polypoid melanoma and superficial spreading melanoma in the same lesion.
\end{abstract}

Keywords: Dermatology; Dermoscopy; Melanoma; Skin neoplasms

\section{INTRODUCTION}

Melanoma is a malignant melanocytic neoplasm which still maintains a high mortality rate and incidence rates that have been universally increasing over the past few years. ${ }^{1}$ Four subtypes of melanoma are classically recognized by using clinical and pathological criteria: superficial spreading, lentigo maligna, acral lentiginous and nodular. This classification allows the clinicopathological tumor differentiation, but not its categorization according to different prognosis., ${ }^{2,3}$ The prognosis of the primary tumor is closely related to its thickness (Breslow), presence of ulceration and, more recently, the presence of 1 or more mitosis $/ \mathrm{mm}^{2}$ in thin melanomas. ${ }^{4}$ Polypoid melanoma is considered an exophytic variant of the nodular form in which the volume of the tumor is located above the skin surface, and it may be pedunculated or sessile. It often appears ulcerated but not necessarily pigmented, which may cause it to be mistaken by benign lesions such as pyogenic granuloma, intradermal nevus, or fibroepithelial polyp. ${ }^{5}$ We present a rare case of polypoid melanoma overlapping the area of a superficial spreading melanoma.

\section{CASE REPORT}

A fifty-eight year-old patient reported a pigmented lesion in the left lumbar region for many years, with progressive growth. Three months before he noticed accelerated growth and ulceration of the lesion. Dermatological examination found a pigmented asymmetric macule, with irregular borders, multiple colors, measuring $3 \times 2 \mathrm{~cm}$ in the left lumbar region. In the lower right area of the lesion there was an erythematous, friable polypoid formation of approximately $1 \mathrm{~cm}$, ulcerated and covered by a serohematic crust (Figure 1). Dermatoscopy showed that the pigmented lesion was formed by a multicomponent pattern with presence of an atypical network, irregular globules and blotches, all irregularly distributed throughout the lesion (Figure 2). The presence of serohematic crust made it difficult to visualize the dermoscopic pattern on the polypoid area. Pathologic examination revealed polypoid superficial spreading melanoma, Clark III, Breslow thickness of $4.3 \mathrm{~mm}$ at the polypoid area and predominant in situ component in adjacent skin (Figure 3). The exam also showed absence of ulceration or regression and the presence of 8 mitoses in 10 high power fields.

Approved by the Advisory Board and accepted for publication on 17.07.2013.

* Work performed at the Universidade Federal de São Paulo (UNIFESP) - São Paulo (SP), Brazil

Conflict of interest: None

Financial funding: None

Universidade Federal de São Paulo (UNIFESP) - São Paulo (SP), Brazil. 

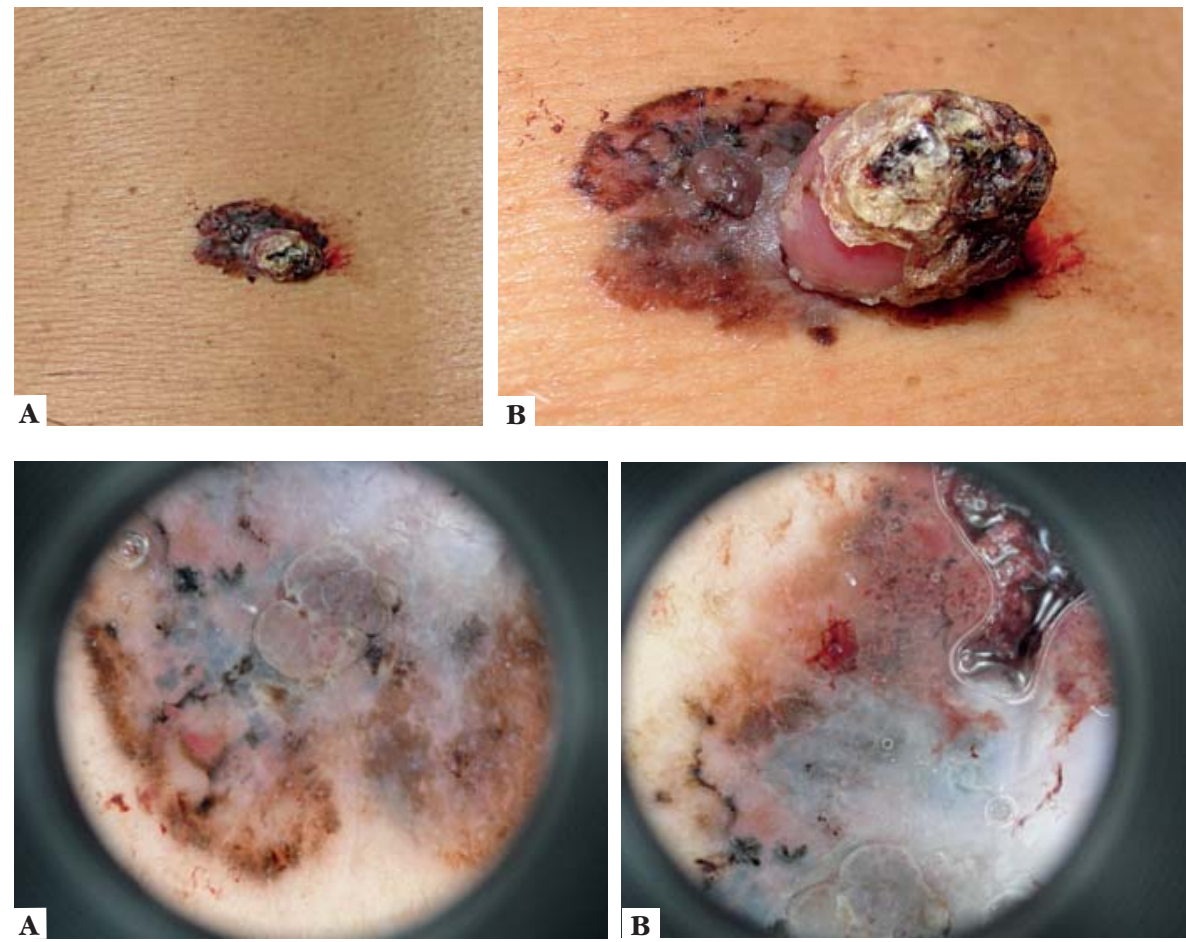

FIGURE 1:

A: Clinical aspect of the lesion on the lumbar area; B: Detailed image showing the polypoid conformation of the lesion
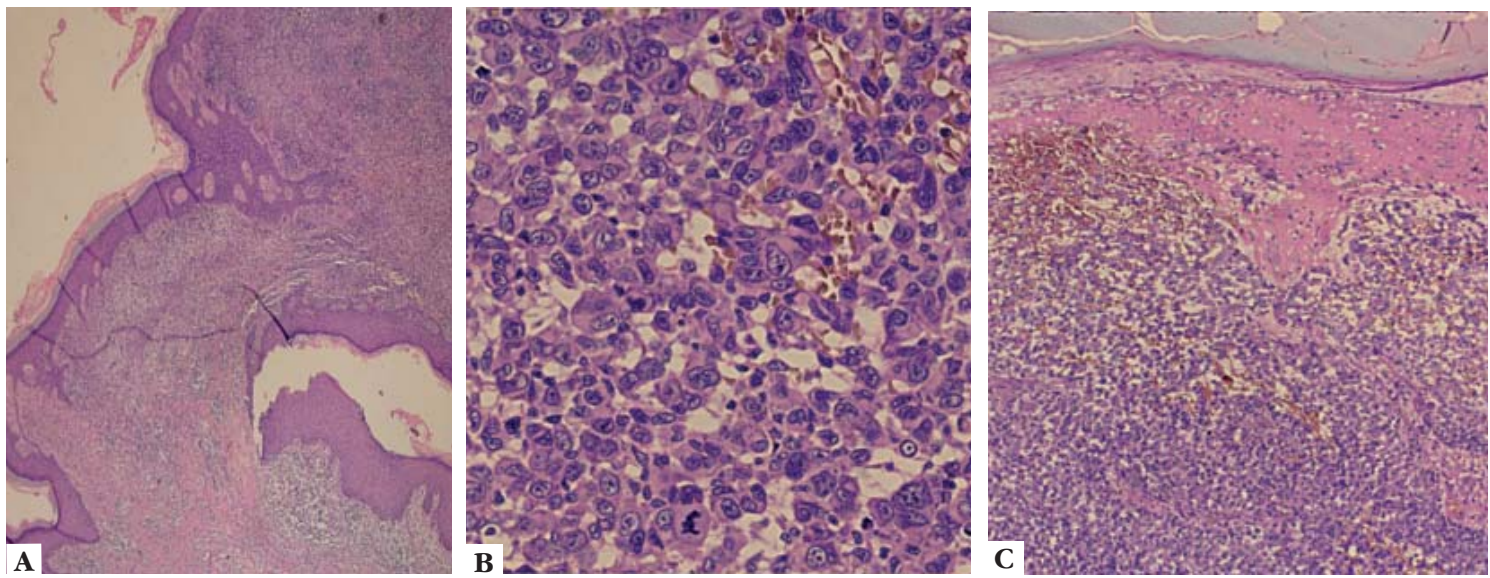

Figure 3: A: Polypoid melanoma pedicle on the insertion area. The adjacent skin surface shows slight proliferation of typical and atypical melanocytes in the basal layer and lymphocytic inflammatory infiltrate in the superficial dermis (HE, 40x); B: Proliferation of atypical melanocytic cells with severe atypia and pagetoid appearance (HE, 400x); C: Top of the polypoid area showing epidermis and dermis with proliferation of atypical melanocytes and areas of necrosis (HE 100x)

\section{DISCUSSION}

The pedunculated melanoma was first described in 1958 by Vogler et al, who considered it as the most aggressive form of nodular melanoma, with almost nonexistent radial growth, followed by rapid vertical growth, creating its pedunculated conformation. It was, by definition, a tumor with more than
$50 \%$ of its area above the epidermis and lateral dissemination inferior to three intraepidermal crests. ${ }^{6}$ McGovern et al, in 1983 classified the polypoid melanoma into pedunculated or sessile. The pedunculated form was defined as a lesion completely above an unaltered cutaneous surface, with which it was 
connected by a pedicle. The sessile form would have at least $50 \%$ of the tumor above the surface. The incidence of polypoid melanoma is extremely variable in the literature, ranging from 2 to $43 \%$ in different studies, probably due to different clinical and pathological criteria used to characterize it. It was believed to be the most aggressive form of melanoma with the worst prognosis. However, multivariate analysis showed that this behavior was not explained by the lesion conformation per se, but rather because this form of melanoma was usually thicker and ulcerated.

\section{REFERENCES}

1. Seer.cancer.gov [Internet]. Howlader N, Noone AM, Krapcho M, Garshell J, Neyman N, Altekruse SF, et al. editors. SEER Cancer Statistics Review, 1975-2010, National Cancer Institute. Bethesda, MD, based on November 2012 SEER data submission, posted to the SEER web site, April 2013. [Cited 2013 Jun 1]. Available from: http://seer.cancer.gov/csr/1975 2010/

2. McGovern VJ, Mihm MC Jr, Bailly C, Booth JC, Clark WH Jr, Cochran AJ, et al. The classification of malignant melanoma and its histologic reporting. Cancer. 1973;32:1446-57.

3. Breuninger H, Köhler C, Drepper H, Bastian B, Bröcker EB, Göhl J, et al. Is acrolentiginous melanoma (ALM) more malignant than superficially spreading melanoma (SSM) at a high-risk site: a matched-pair comparison between 113 ALM and SSM within the scope of a multicenter study Hautarzt. 1994:45:529-31.

4. Balch CM, Gershenwald JE, Soong SJ, Thompson JF, Atkins MB, Byrd DR, et al. Final version of 2009 AJCC melanoma staging and classification. J Clin Oncol. 2009;27:6199-206

5. Cutler K, Chu P, Levin M, Wallack M, Don PC, Weinberg JM. Pedunculated malignant melanoma. Dermatol Surg. 2000;26:127-9.

6. Vogler WR, Perdue GD, Wilkins SA Jr. A clinical evaluation of malignant melanoma. Surg Gynecol Obstet. 1958;106:586-94.

7. McGovern VJ, Shaw HM, Milton GW. Prognostic significance of polypoid configuration in malignant melanoma. Histopathology. 1983;7:663-72.

8. Plotnick H, Rachmaninoff N, VandenBerg HJ Jr. Polypoid melanoma: a virulent variant of nodular melanoma. J Am Acad Dermatol. 1990;23:880-4.

9. De Giorgi V, Massi D, Gerlini G, Mannone F, Quercioli E, Carli P. Immediate local and regional recurrence after the excision of a polypoid melanoma: tumor dormancy or tumor activation? Dermatol Surg. 2003;29:664-7.

10. Shaw HM, Thompson JF. Polypoid melanoma is not rare. Br J Dermatol. 1996;135:333-4.
Clinically, it evolves with rapid growth and histopathologically it has a higher degree of cellular atypia, nuclear and cellular pleomorphism and higher mitotic index that can also explain the apparent poor prognosis. ${ }^{7-10}$

\section{CONCLUSION}

We present a rare case of polypoid melanoma over an area of superficial spreading melanoma. The case highlights the importance of prognostic factors linked to melanoma, independent of histological subtype.

\author{
MAILING ADDRESS: \\ Renato Shintani Hikawa \\ Rua Borges Lagoa, 508 - Vila Clementino \\ 04038-001 - São Paulo - SP \\ Brazil \\ E-mail: renato71@gmail.com
}

How to cite this article: Hikawa RS, Kanehisa ES, Enokihara MMSS, Enokihara MY, Hirata SH. Polypoid melanoma and superficial spreading melanoma - different subtypes in the same lesion. An Bras Dermatol. 2014;89(4):666-8. 